\title{
Cefquinome sulfate behavior after intramammary administration in healthy and infected cows
}

\author{
A. Zonca, ${ }^{\star}$ M. Gallo, ${ }^{\star}$ C. Locatelli, $†$ S. Carli, ${ }^{\star}$ P. Moroni, $\ddagger$ R. Villa, ${ }^{\star}$ and P. Cagnardi ${ }^{\star 1}$ \\ *Università degli Studi di Milano, Department of Veterinary Sciences and Technologies for Food Safety, 20133 Milan, Italy \\ †Università degli Studi di Milano, Department of Veterinary Pathology, Hygiene and Public Health, 20133 Milan, Italy \\ ¥Quality Milk Production Services, Cornell University, 22 Thornwood Drive, Ithaca, NY 14850
}

\section{ABSTRACT}

Maintenance of adequate drug concentration at the site of infection is an important problem in mastitis antibiotic therapy, and the efficacy of intramammary $\beta$-lactams can be optimized by maintaining the drug concentration at the site of infection above the minimum inhibitory concentration (MIC) as long as possible. The most important pharmacokinetic and pharmacodynamic parameter for efficacy evaluation is time during which drug concentrations exceed the MIC $(t>$ MIC). In this study, we assessed the pharmacokinetic profile of cefquinome (CFQ) after repeated intramammary administration in healthy cows and cows subclinically infected with Staphylococcus aureus as well as the MIC of Staph. aureus field strains. In addition, the degree of drug passage was investigated from udder to bloodstream by measuring systemic drug absorption in healthy and infected animals. Cefquinome concentrations were quantified by HPLC (UV-visible detection) in milk samples collected from quarters and from blood serum samples. The systemic drug absorption was negligible in healthy and subclinically infected animals (maximum concentration $0.09 \pm 0.02$ and $0.1 \pm 0.01$ $\mu \mathrm{g} / \mathrm{mL}$ in healthy and subclinically infected animals, respectively). The $\mathrm{MIC}_{90}$ value for $\mathrm{CFQ}$ in Staph. aureus field strains $(\mathrm{n}=20)$ was $0.24 \mu \mathrm{g} / \mathrm{mL}$. The pharmacokinetic and pharmacodynamic evaluation, determined by $t>\mathrm{MIC}$, showed an equal persistence of CFQ in all quarters, indicating an equivalent activity of the drug regardless of the pathological status of the udder. Moreover, with literature data regarding $\mathrm{CFQ}$ MIC, the $t>$ MIC has been calculated for other bacterial species.

Key words: cefquinome sulfate, lactating intramammary treatment, minimum inhibitory concentration

Received December 20, 2010.

Accepted March 31, 2011.

${ }^{1}$ Corresponding author: petra.cagnardi@unimi.it

\section{INTRODUCTION}

The success of antimicrobial therapies depends on various factors, such as the location and susceptibility of microorganisms, the animal's health, and the characteristics of the administered drug (Barragry, 1994).

This study was part of a more extensive research aiming to assess the influence of the mammary health status on the pharmacokinetic (PK) parameters of intramammary (IMM)-administered cephalosporins. In the paper by Cagnardi et al. (2010), concerning a third-generation cephalosporin (cefoperazone), we described the drug kinetic behavior in healthy and in subclinically infected lactating cows after a single IMM administration. In the present paper, we continue the investigation about cefquinome (CFQ), a fourth-generation cephalosporin. Cefquinome is approved only for veterinary use and it is highly stable to $\beta$-lactamases. Because of its broad spectrum, it has highly, moderate, and good activity against Enterobacteriaceae, Pseudomonas aeruginosa, and staphylococci species, respectively. In lactating cows it is used IMM for the treatment of clinical coliform and other bacterial mastitis (Streptococcus uberis, Streptococcus dysgalactiae, Staphylococcus aureus; Shpigel and Schmid, 1997; CVMP, 2003; Prescott, 2006) as indicated in the label of the commercial product (Cobactan L, Intervet, Milan, Italy; Summary of Product Characteristics). Cefquinome, like other fourth-generation cephalosporins, possesses improved antibacterial activity compared with second- and third-generation cephalosporins and is highly effective against gram-negative bacteria. Thus, CFQ is effectively used for the therapy of acute mastitis sustained by Escherichia coli (Shpigel et al., 1997); nevertheless, clinical and in vitro evidence suggests that CFQ may also be of value in the treatment of Staph. aureus mastitis (Limbert et al., 1991; Böttner et al., 1995; Guerin-Faublée et al., 2003; Shpigel et al., 2006).

Because cephalosporins act as time-dependent antimicrobials, the most appropriate pharmacokinetic/ pharmacodynamic $(\mathbf{P K} / \mathbf{P D})$ parameter to describe drug efficacy is the time during which the drug's concentration exceeds the MIC $(\boldsymbol{t}>$ MIC; McKellar et 
al., 2004; Wagner and Erskine, 2006). During the present study, to optimize the CFQ dosage regimen, we assessed the MIC on Staph. aureus and calculated the $t$ $>$ MIC. To complete the investigation, literature data about CFQ MIC were correlated to the observed drug concentrations and $t>$ MIC for other bacterial species are proposed.

Generally, weak acids (such as $\beta$-lactam antibiotics) penetrate the blood-mammary barrier poorly, due to the degree of ionization at physiological $\mathrm{pH}$. In an in vitro study, Ehinger et al. (2006) demonstrated that CFQ did not diffuse into simulated systemic circulation after IMM administration. As in our previous study on cefoperazone (Cagnardi et al., 2010), systemic absorption of CFQ after IMM administration was investigated here, as were possible differences between healthy and subclinically infected udders due to changes in vascular permeability caused by IMI (Gehring and Smith, 2006).

Therefore, the aims of this study were to (1) assess the PK parameters after repeated IMM administration of CFQ in healthy and Staph. aureus-infected cows; (2) calculate the PK/PD parameters on different bacterial species; and (3) investigate the passage of CFQ through the blood-mammary barrier.

\section{MATERIALS AND METHODS}

\section{Animal Selection}

One hundred forty milking cows from a farm in northern Italy were tested for Staph. aureus, and $40 \%$ were infected. Twelve lactating cows (Italian Frisona), 600 to $750 \mathrm{~kg}$ of BW $(670 \pm 53 \mathrm{~kg})$, in first or second lactation were selected. All cows were provided with water ad libitum and a drug-free TMR, according to their nutrient requirements (NRC, 2001). At the onset of their use, the animals were between 50 and 150 DIM $(105 \pm 39 \mathrm{~d})$. The cows were milked twice daily in an 8 +8 milking parlor. Milk production was $44.1 \pm 7.6 \mathrm{~L} / \mathrm{d}$ (range from 30 to $55 \mathrm{~L} / \mathrm{d}$ ).

\section{Preliminary Bacteriology}

The bacteriological sampling and testing were carried out as reported in Cagnardi et al. (2010). Infection status was defined according to the procedures recommended by National Mastitis Council (NMC, 1999), and SCC was determined for each sample by using an automated fluorescent microscopic somatic cell counter (Bentley Somacount, Bentley Instruments, Chaska, $\mathrm{MN})$. Based on the presence or absence of Staph. aureus infection in quarters, cows were divided into healthy $(\mathbf{H})$ and subclinically infected (SI) groups. Positivity for Staph. aureus was monitored for 3 wk during the following period by subsequent samplings in selected cows belonging to the groups.

\section{MIC Determination}

Twenty isolates from infected quarters $(\mathrm{n}=13)$ and from other animals belonging to the same farm but not included in the study $(\mathrm{n}=7)$ were tested for antimicrobial susceptibility to CFQ by the determination of MIC according to the microdilution broth method as recommended by NCCLS (2002). Cefquinome sulfate with purity grade of $80.1 \%$ (Intervet, Milan, Italy) was dissolved and diluted in sterile distilled water. Isolates were prepared as described by Cagnardi et al. (2010).

\section{Treatment and Sampling}

After accurate milking and teat disinfection, each quarter of each cow was administered every $12 \mathrm{~h}$ with $75 \mathrm{mg}$ IMM of CFQ sulfate (Cobactan L, Intervet, Milan, Italy) for 3 consecutive treatments. All quarters were administered CFQ, regardless of infection status, to reach the maximum dose (300 $\mathrm{mg}$ of CFQ per animal each $12 \mathrm{~h}$ ).

Milk samples were collected by hand separately from individual teats before (to) and after last drug administration $(2,8$, and $12 \mathrm{~h})$. Then, further samples were collected every $12 \mathrm{~h}$ until the 10th milking. Cistern milk samples were collected after discarding the first streams of milk. Differences in milk pH due to drug administration or infection status of the udder were recorded at t0 and $0.5 \mathrm{~h}$ milk samples at room temperature.

Blood samples were collected from the jugular vein at t0 (before drug administration), after each drug administration at $2,4,8$, and $12 \mathrm{~h}$, and after the last treatment at 24,36 , and $48 \mathrm{~h}$. Subsequently, samples were centrifuged $(1,500 \times g, 10 \mathrm{~min}$ at room temperature $)$ to obtain serum and stored at $-20^{\circ} \mathrm{C}$ pending assay.

\section{Sample Extraction and HPLC Analyses}

Cefquinome was extracted from milk and blood samples and the residues were analyzed by HPLC as reported by Cagnardi et al. (2010). To the authors' knowledge, no published paper has reported the existence of active CFQ metabolites in milk, and thus their presence was not evaluated.

\section{Intralaboratory Validation of Analytical Method}

The calibration curves were made in blank bovine milk and serum, diluting the original CFQ stock solution $(1 \mathrm{mg} / \mathrm{mL})$ to obtain final concentrations of CFQ ranging from 0.01 to $40 \mu \mathrm{g} / \mathrm{mL}$. The HPLC method 
was validated for both matrices and was specific, linear (range 0.01 to $40 \mu \mathrm{g} / \mathrm{mL}$ for both matrices), precise (CV from 2.2 to $7.6 \%$ in milk and from 1.8 to $5.7 \%$ in serum), and accurate (between $+0.4 \%$ and $-9.95 \%$ in milk and between $+9.5 \%$ and $-0.4 \%$ in serum). The lower and upper limits of quantification were 0.01 and $40 \mu \mathrm{g} / \mathrm{mL}$, respectively, for milk and serum. Samples with concentrations higher than the upper limit of quantification were quantified after dilution. The limit of detection was $0.001 \mu \mathrm{g} / \mathrm{mL}$ for both matrices.

\section{Pharmacokinetic Analysis}

As reported by Stockler et al. (2009a), no specific PK model is available to describe IMM kinetics. Thus, a noncompartmental analysis was carried out on milk and serum drug concentrations using the WinNonLin 5.2.1 software (model 201; Pharsight Corp., Mountain View, CA) to obtain comparable parameters after kinetic analyses of the concentration-time profile in both matrices. Mean residence time (MRT) was determined from the following equation (Gibaldi and Perrier, 1982):

$$
\mathrm{MRT}=\mathrm{AUMC} / \mathrm{AUC},
$$

where AUMC is area under the moment curve and AUC is area under serum or milk concentration-time curve.

\section{Statistical Analysis}

Differences were investigated between healthy and infected animals. Unpaired $t$-test with Welch correction (variances unequal) was performed on elimination half-life, maximum concentration, $\mathrm{AUC}_{\text {last }}$ and $\mathrm{MRT}_{\text {last }}$, where last $=$ calculated from 0 to last time point, and on $\mathrm{pH}$ values before and after treatment (InStat 3.0 GraphPad, La Jolla, CA). The ANOVA test was performed to evaluate differences among groups of quarters. In both tests, differences with $P<0.05$ were considered significant.

\section{RESULTS}

Drug quantification was carried out in samples from single quarters, thus results from group $\mathrm{H}$ were identified as healthy quarters $(\mathbf{H Q}, \mathrm{n}=24)$, whereas results from group SI were divided into infected quarters $(\mathbf{I Q}$, $\mathrm{n}=13$ ) and suspected quarters (SQ; i.e., healthy quarters of infected animals, $\mathrm{n}=11$ ).

Cefquinome was detected in milk until $108 \mathrm{~h}$ (ninth milking) in IQ and HQ and until $96 \mathrm{~h}$ (eighth milking) in SQ (Figure 1). Serum concentrations were variably quantifiable with low values in all animals (Figure 2). In serum of healthy subjects, CFQ was detectable in all

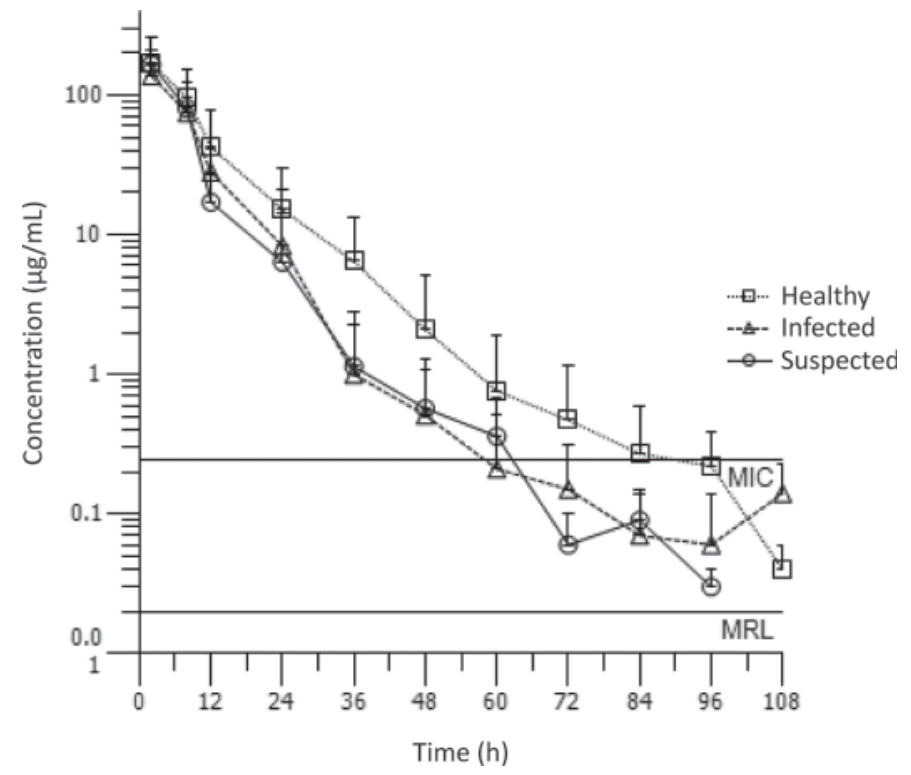

Figure 1. Milk concentration in healthy (HQ), infected (IQ), and suspected quarters (SQ) after the last administration of cefquinome at the dose of $75 \mathrm{mg} /$ quarter plotted with MIC $(0.24 \mu \mathrm{g} / \mathrm{mL})$ and maximum residual limit (MRL; $0.02 \mu \mathrm{g} / \mathrm{mL}$ ).

animals until $32 \mathrm{~h}$ and in only 1 subject until $60 \mathrm{~h}$. In infected cows, all animals showed quantifiable concentrations until $48 \mathrm{~h}$ and in 4 subjects until $72 \mathrm{~h}$.

Mean milk and serum PK parameters are shown in Table 1. The kinetic analysis in serum was carried out on data after the last treatment. Mean milk $\mathrm{pH}$ values measured at t0 and $0.5 \mathrm{~h}$ after first treatment are shown in Table 2. The drug inhibitory concentrations

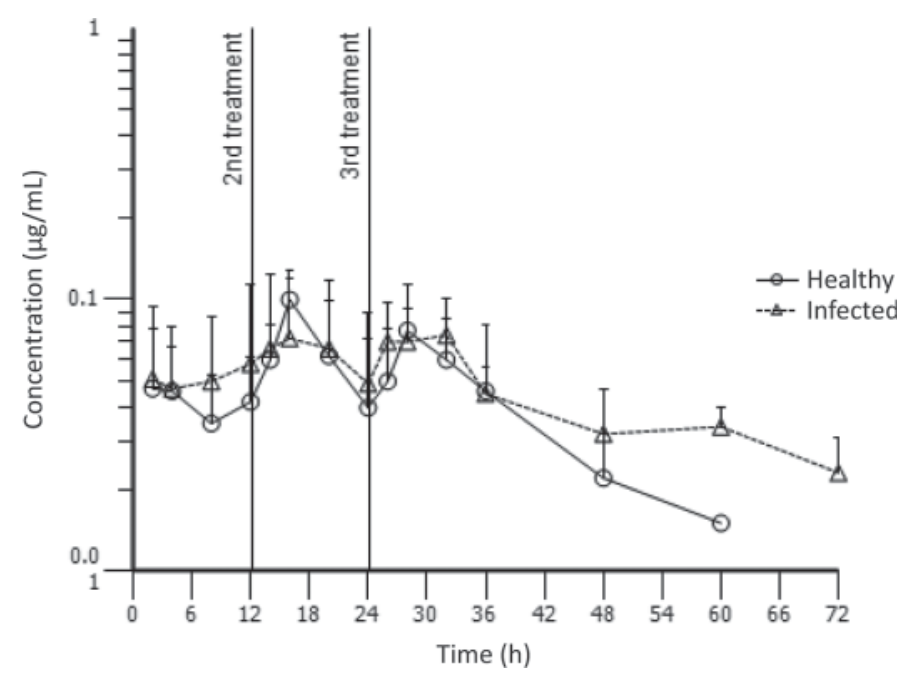

Figure 2. Mean serum concentration $( \pm \mathrm{SD})$ in healthy and infected animals during intramammary administration of cefquinome at a dose of $75 \mathrm{mg} /$ quarter each $12 \mathrm{~h}$. Vertical lines indicate second and third treatment (first treatment corresponds to time 0 ). 
Table 1. Mean $( \pm \mathrm{SD})$ milk and serum pharmacokinetic parameters after intramammary administration of cefquinome in healthy (HQ), infected (IQ), and suspected quarters (SQ) in healthy and infected animals

\begin{tabular}{|c|c|c|c|}
\hline Parameter $^{1}$ & $\begin{array}{l}\text { Healthy quarter } \\
\qquad(\mathrm{n}=24)\end{array}$ & $\begin{array}{l}\text { Infected quarter } \\
\qquad(\mathrm{n}=13)\end{array}$ & $\begin{array}{l}\text { Suspected quarter } \\
\quad(\mathrm{n}=11)\end{array}$ \\
\hline \multicolumn{4}{|l|}{ Milk } \\
\hline $\mathrm{t}_{1 / 2 \lambda \mathrm{z}}(\mathrm{h})$ & $6.21 \pm 3.95$ & $4.20 \pm 2.48$ & $\begin{array}{r}4.43 \pm 2.1 \\
\end{array}$ \\
\hline $\mathrm{T}_{\max }(\mathrm{h})$ & $2^{*(\mathrm{SQ})} \pm 0$ & $2^{*(\mathrm{SQ})} \pm 0$ & $3.2^{*(\mathrm{HQ} ; \mathrm{IQ})} \pm 2.68$ \\
\hline $\mathrm{C}_{\max }(\mu \mathrm{g} / \mathrm{mL})$ & $171.89 \pm 41.01$ & $137.77 \pm 48.34$ & $168.34 \pm 89.55$ \\
\hline $\mathrm{AUC}_{\text {last }}(\mathrm{h} \cdot \mu \mathrm{g} / \mathrm{mL})$ & $1,592.99 \pm 673.4$ & $1,201.79 \pm 425.53$ & $1,242.62 \pm 618.81$ \\
\hline $\mathrm{AUC}_{\text {inf }}(\mathrm{h} \cdot \mu \mathrm{g} / \mathrm{mL})$ & $1,780.74 \pm 832.57$ & $1,337.78 \pm 669.64$ & $1,320.75 \pm 704.78$ \\
\hline $\operatorname{AUMC}_{\text {last }}(\mathrm{h} \cdot \mathrm{h} \cdot \mu \mathrm{g} / \mathrm{mL})$ & $11,436.07 \pm 7,628.29$ & $16,413.12^{*(\mathrm{SQ})} \pm 8,006.82$ & $7,114.22^{*(\mathrm{IQ})} \pm 4,330.01$ \\
\hline $\mathrm{MRT}_{\text {last }}(\mathrm{h})$ & $6.58 \pm 2.05$ & $6.39 \pm 1.47$ & $5.79 \pm 2.12$ \\
\hline \multirow[t]{2}{*}{$t>\mathrm{MIC}(\mathrm{h})$} & $54 \pm 34$ & $42 \pm 18$ & $43 \pm 16$ \\
\hline & Healthy cow $(\mathrm{n}=6)$ & Infected cow $(\mathrm{n}=6)$ & \\
\hline $\mathrm{t}_{1 / 2 \lambda z}(\mathrm{~h})$ & $11.43 \pm 7.09$ & $17.3 \pm 7.7$ & \\
\hline $\mathrm{T}_{\max }(\mathrm{h})$ & $29.50 \pm 3.00$ & $29.5 \pm 3.00$ & \\
\hline $\mathrm{C}_{\max }(\mu \mathrm{g} / \mathrm{mL})$ & $0.09 \pm 0.02$ & $0.1 \pm 0.01$ & \\
\hline $\mathrm{AUC}_{\text {last }}(\mathrm{h} \cdot \mu \mathrm{g} / \mathrm{mL})$ & $1.07 \pm 0.50$ & $2.39 \pm 1.07$ & \\
\hline $\mathrm{AUMC}_{\text {last }}(\mathrm{h} \cdot \mathrm{h} \cdot \mu \mathrm{g} / \mathrm{mL})$ & $9.54 \S \pm 6.76$ & $58.46 \S \pm 33.75$ & \\
\hline $\mathrm{MRT}_{\text {last }}(\mathrm{h})$ & $8.31 \pm 3.10$ & $14.72 \pm 8.93$ & \\
\hline \multicolumn{4}{|c|}{$\begin{array}{l}{ }^{1} \mathrm{t}_{1 / 2 \lambda \mathrm{z}}=\text { elimination half-time; } \mathrm{T}_{\max }=\text { observed time for } \mathrm{C}_{\max } ; \mathrm{C}_{\max }=\text { maximum drug concentration; } \mathrm{AUC}_{\mathrm{las}} \\
=\text { area under milk/serum concentration-time curve; } \mathrm{AUC}_{\mathrm{inf}}=\text { area under the concentration-time curve from } \\
\text { to infinity; } \mathrm{AUMC}_{\text {last }}=\text { area under the moment curve; } \mathrm{MRT}_{\text {last }}=\text { mean residence time; } t>\mathrm{MIC}=\text { time during } \\
\text { which drug concentrations exceeded the MIC. }\end{array}$} \\
\hline \multicolumn{4}{|c|}{$\begin{array}{l}\text { *Statistically significant }(P<0.05) \text { difference between quarters (ANOVA); letters in parentheses show groups } \\
\S \text { Statistically significant }(P<0.05) \text { difference between healthy and infected animals ( } t \text {-test Welch correction) }\end{array}$} \\
\hline
\end{tabular}

toward Staph. aureus field strains $(\mathrm{n}=20)$ ranged from 0.12 to $0.48 \mu \mathrm{g} / \mathrm{mL}$; the calculated $\mathrm{MIC}_{90}$ was $0.24 \mu \mathrm{g} /$ $\mathrm{mL}$. The $t>$ MIC values (Table 1 ) in milk were $54 \pm$ $34 \mathrm{~h}, 42 \pm 18 \mathrm{~h}$, and $43 \pm 16 \mathrm{~h}$ in $\mathrm{HQ}$, IQ, and SQ, respectively $(P>0.05)$.

The $\mathrm{MIC}_{90}$ collected from literature data on various bacterial strains and the calculated $t>$ MIC are reported in Table 3 . Considering $\mathrm{MIC}_{90}$ and $t>\mathrm{MIC}$, the activity recorded against Staphylococcus spp. and Staph. aureus was relatively poor.

\section{DISCUSSION}

Fourth-generation cephalosporins are valuable extended-spectrum drugs for treatment of serious human infections and not first-choice antimicrobial agents in animals. To limit the selection of resistant bacteria, fourth-generation cephalosporins should be reserved for use where susceptibility testing indicates that alternatives are not available (Prescott, 2006; FDA, 2008). Cefquinome is developed solely for veterinary use and is licensed in Europe but not in the United States.

Pharmacokinetic studies are usually carried out in healthy animals. However, drug behavior in unhealthy animals could be modified by various factors, as might occur, for example, during subclinical IMI in cows. Therefore, in this study, we investigated IMM administration in healthy cows and in cows infected with Staph. aureus. The subclinical stage was preferred to an acute
IMI phase, because serious gland modifications could affect results in an acute infection.

When planning the study, we supposed that SQ could be considered as control quarters for infected animals and thus were considered as a separate group; conversely to what we supposed, similar profiles in the different pathological conditions (HQ, IQ, and SQ) and a negligible influence of the udder environment were observed in kinetics of CFQ after IMM treatments.

After administrations, CFQ was generally quantifiable in milk for $108 \mathrm{~h}$ in HQ and IQ and for $96 \mathrm{~h}$ in SQ. Some evidence suggests that cows with low milk production eliminate IMM drugs more slowly than cows with higher production (Gehring and Smith, 2006). In this study, as observed in a similar study with cefoperazone (Cagnardi et al., 2010), no correlation was

Table 2. Mean $( \pm \mathrm{SD})$ milk $\mathrm{pH}$ in healthy $(\mathrm{HQ})$, infected (IQ), and suspected quarters $(\mathrm{SQ})$ before $(\mathrm{t} 0)$ and after the first treatment $(0.5$ h)

\begin{tabular}{lccc}
\hline & $\mathrm{HQ}$ & $\mathrm{IQ}$ & $\mathrm{SQ}$ \\
Time & $(\mathrm{n}=24)$ & $(\mathrm{n}=13)$ & $(\mathrm{n}=11)$ \\
\hline t0 & $6.98^{*(\mathrm{IQ})} \pm 0.09$ & $6.91 \S^{*(\mathrm{HQ})} \pm 0.07$ & $6.92 \S \pm 0.05$ \\
$0.5 \mathrm{~h}$ & $6.96 \pm 0.18$ & $7.02 \S \pm 0.15$ & $7.01 \S \pm 0.12$ \\
\hline
\end{tabular}

*Statistically significant $(P<0.05)$ difference between quarters (ANOVA); letters in parentheses show groups.

§Statistically significant $(P<0.05)$ difference between healthy and infected animals ( $t$-test Welch correction). 
Table 3. Minimum inhibitory concentrations $\left(\mathrm{MIC}_{90}\right)$ of cefquinome against common mastitis-causing bacteria from Europe and North America between 1990 and 2002 (Shpigel and Schmid, 1997; Schmid and Thomas, 2002; Ehinger et al., 2006) and the calculated $t>$ MIC (time during which drug concentrations exceeded the MIC)

\begin{tabular}{lcc}
\hline Species $(\mathrm{n})$ & $\begin{array}{c}\mathrm{MIC}_{90} \\
(\mu \mathrm{g} / \mathrm{mL})\end{array}$ & $\begin{array}{c}t>\mathrm{MIC} \\
(\mathrm{h})\end{array}$ \\
\hline Streptococcus spp. $(759)$ & 0.25 to 0.5 & $46-54$ \\
Streptococcus agalactiae $(281)$ & $<0.03$ to 0.13 & $94-64$ \\
Streptococcus dysgalactiae $(404)$ & $<0.008$ to 0.25 & $94-54$ \\
Streptococcus uberis $(529)$ & $<0.03$ to 0.25 & $94-64$ \\
Enterococcus spp. $(127)$ & 1.0 to $>4.0$ & $44-28$ \\
Staphylococcus spp. $(580)$ & 0.5 to 2.0 & $46-32$ \\
Staphylococcus aureus $(229)$ & 0.5 to 1.0 & $46-44$ \\
Actinomyces pyogenes $(43)$ & 1.0 & 44 \\
Enterobacteriaceae $(323)$ & 0.13 & 64 \\
Escherichia coli $(637)$ & 0.06 to 0.13 & $72-64$ \\
Klebsiella spp. $(31)$ & 0.13 & 64 \\
Pseudomonas spp. $(55)$ & $>4.0$ & 28 \\
\hline
\end{tabular}

observed between milk production and drug elimination after IMM administration.

Residue depletion studies have demonstrated that CFQ can be detected in kidney at $24 \mathrm{~h}$ after IMM administration (CVMP, 1995), thus confirming the systemic absorption of the drug. Drug amounts in serum samples were low in healthy and infected animals with a maximum concentration (Cmax) of approximately $0.1 \mu \mathrm{g} / \mathrm{mL}$ in both groups (Table 1). In healthy animals, serum concentrations were detected for a short time (i.e., in only 1 subject until $60 \mathrm{~h}$ ). In infected cows, serum concentrations were more persistent and in 4 subjects the drug was still quantifiable $72 \mathrm{~h}$ after administration (Figure 2). However, considering the kinetic results and, in particular, the parameter of the total exposure of the body to the drug (as AUC), no differences were observed and thus a negligible influence of udder status in the absorption of CFQ could be demonstrated in our animals.

Considering milk pH (Table 2), our results are not straightforward. Unexpectedly, a more acidic milk was observed in IQ $(P<0.05)$ at t0, and the behavior of milk pre- and posttreatment in SQ and IQ was similar, supporting the finding, documented by Oshima and Yoshida (1988) and Holdaway et al. (1996), that $\mathrm{pH}$ is not a good indicator of mastitis. The slight acidification we expected after IMM administration was not observed in HQ; on the contrary, a slight basification $(P<0.05)$ was reported in the other quarters (IQ and $\mathrm{SQ}$ ). The reason for these changes is not completely clear and because the $\mathrm{pH}$ evaluation was conducted only after the first treatment, we are not able to estimate the influence of the 2 further treatments on milk $\mathrm{pH}$, even though a possible milk acidification could be supposed. As stated above, in our SI cows, no differences in absorption were observed, and milk $\mathrm{pH}$ and CFQ acid dissociation constant $\left(\mathrm{p} K_{\mathrm{a}}=2.51\right.$ and 2.91) did not seem to influence drug diffusion from milk to serum (Gehring and Smith, 2006). On the contrary, in the study with cefoperazone, slightly higher absorption was observed in infected animals and attributed to the chronic alteration of mammary membrane due to subclinical infections (Cagnardi et al., 2010).

This relevant finding could be important when considering that withdrawal times are generally established in healthy animals and, in the case of CFQ, correspond to 4 and $5 \mathrm{~d}$ for meat and milk, respectively. Because no differences were observed in systemic CFQ absorption in healthy and infected animals and in milk kinetics among HQ, IQ, and SQ, we can confirm the validity of these withdrawal times for infected animals also.

The $\mathrm{MIC}_{90}$ value of $\mathrm{CFQ}$ for Staph. aureus field strains was low $(0.24 \mu \mathrm{g} / \mathrm{mL})$ and, as shown in the Figure 1, milk drug concentrations were maintained above the MIC for a long period. The elimination halflives in milk from all groups of quarters were similar: $6.21 \pm 3.95 \mathrm{~h}$ in $\mathrm{HQ}, 4.20 \pm 2.48 \mathrm{~h}$ in IQ, and $4.43 \pm$ $2.1 \mathrm{~h}$ in $\mathrm{SQ}(P>0.05)$, and the calculated $t>\mathrm{MIC}$ were comparable: $54 \mathrm{~h}$ in HQ, $42 \mathrm{~h}$ in IQ, and $43 \mathrm{~h}$ in SQ $(P>0.05)$. This means that in all quarters the microorganisms were exposed to drug activity for a long period and indicated good efficacy of CFQ against Staph. aureus. At the end of the study, the SI group animals were monitored for health conditions and degree of infection. The results were negative; that is, no Staph. aureus strains were isolated in milk samples collected from IQ, thus confirming the efficacy of CFQ treatment, even though CFQ is not the elective drug for subclinical mastitis therapy. The overall positive CFQ performance after IMM injection against Staph. aureus infections was also confirmed by Bradley and Green (2009). As reported by Shpigel et al. (2006), the cure rate was low after systemic administration of CFQ at drying-off in dairy cows affected by subclinical Staph. 
aureus mastitis; thus, the IMM therapeutic scheme seems to be more appropriate.

As reported by Stockler et al. (2009b), milk fraction seems to influence the PK and residue depletion of cephapirin, and bucket milk seems to be the best sample, because it reflects the whole condition of the mammary gland. In our study, we collected cisternal milk and it would be interesting to evaluate if this choice could have influenced our PK and antimicrobial results.

The $\mathrm{MIC}_{90}$ collected from literature data on various bacterial strains and the $t>$ MIC calculated are reported in Table 3 . These data confirm the good activity of CFQ, particularly against Strep. agalactiae, Strep. dysgalactiae, Strep. uberis, E. coli, and Enterobacteriaceae. It should be noted that the standard procedure for MIC determination uses Mueller-Hinton broth. Constable and Morin (2003) stated that the presence of milk during in vitro MIC determination could markedly decrease the activity of antibiotics, mainly due to drug protein or lipid binding or to the difference in $\mathrm{pH}$ between Mueller-Hinton broth and milk. Thus, milk, and particularly milk collected from IQ, would most likely represent the best test medium to investigate the efficacy of drugs administered IMM.

\section{CONCLUSIONS}

The CFQ sulfate product administered every $12 \mathrm{~h}$ IMM in every quarter at the maximum approved dose of $75 \mathrm{mg}$ of CFQ per quarter did not cause any adverse effects and was well tolerated. Systemic CFQ absorption was comparable in healthy and infected animals. The $\mathrm{MIC}_{90}$ value of CFQ for Staph. aureus field strains was low $(0.24 \mu \mathrm{g} / \mathrm{mL})$. The 3 IMM administrations of $\mathrm{CFQ}$ in $\mathrm{H}$ and $\mathrm{SI}$ animals showed a similar $t>\mathrm{MIC}$ in all quarters $(54,43$, and $42 \mathrm{~h}$ in HQ, SQ, and IQ, respectively), indicating that Staph. aureus strains were exposed to antibiotic activity for a long time in all animals. At the end of our study, all the SI animals were negative for Staph. aureus, confirming the validity of dosage scheme adopted.

\section{ACKNOWLEDGMENTS}

The authors kindly thank the breeder and the farm "Azienda Agricola Groppelli" (Bagnolo Cremasco, Lodi, Italy) for the assistance provided. The authors are also grateful to Intervet (Milan, Italy) for supplying cefquinome analytical standard.

\section{REFERENCES}

Barragry, T. B. 1994. Bovine mastitis. Pages 655-688 in Veterinary Drug Therapy. Lea \& Febiger, Philadelphia, PA.
Böttner, A., P. Schmid, and R. Humke. 1995. In vitro efficacy of Cefquinome (INN) and other anti-infective drugs against bovine bacterial isolates from Belgium, France, Germany, the Netherlands and the United Kingdom. Zentralbl. Veterinarmed. B 42:377-383.

Bradley, A. J., and M. J. Green. 2009. Factors affecting cure when treating bovine clinical mastitis with cephalosporin-based intramammary preparations. J. Dairy Sci. 92:1941-1953.

Cagnardi, P., R. Villa, M. Gallo, C. Locatelli, S. Carli, P. Moroni, and A. Zonca. 2010. Cefoperazone sodium preparation behavior after intramammary administration in healthy and infected cows. J. Dairy Sci. 93:4105-4110.

Constable, P. D., and D. E. Morin. 2003. Treatment of clinical mastitis using antimicrobial susceptibility profiles for treatment decisions. Vet. Clin. North Am. Food Anim. Pract. 19:139-155.

CVMP. 1995. Cefquinome. Summary Report. EMEA/MRL/005/95. European Agency for the Evaluation of Medicinal Products, London, UK.

CVMP. 2003. Cefquinome (Extension to Horses). Summary Report (3). EMEA/MRL/883/03-FINAL. European Agency for the Evaluation of Medicinal Products. London. UK.

Ehinger, A. M., H. Schmidt, and M. Kietzmann. 2006. Tissue distribution of cefquinome after intramammary and "systemic" administration in the isolated perfused bovine udder. Vet. J. 172:147-153.

FDA. 2008. CVM Updates, Cephalosporin Order of Prohibition Questions and Answers, July 16, 2008. US Food and Drug Administration, Washington, DC.

Gehring, R., and G. W. Smith. 2006. An overview of factors affecting the disposition of intramammary preparations used to treat bovine mastitis. J. Vet. Pharmacol. Ther. 29:237-241.

Gibaldi, M., and D. Perrier. 1982. Noncompartmental analysis based on statistical moment Theory. Pages 409-417 in Pharmacokinetics. Marcel Dekker Inc., New York, NY.

Guerin-Faublée, V., G. Carret, and P. Houffschmitt. 2003. In vitro activity of 10 antimicrobial agents against bacteria isolated from cows with clinical mastitis. Vet. Rec. 152:466-471.

Holdaway, R. J., C. W. Holmes, and I. J. Steffert. 1996. A comparison of indirect methods for diagnosis of subclinical intramammary infection in lactating dairy cows. Aust. J. Dairy Technol. 51:64-78.

Limbert, M., D. Isert, N. Klesel, A. Markus, K. Seeger, G. Seibert, and E. Schrinner. 1991. Antibacterial activities in vitro and in vivo and pharmacokinetics of cefquinome (HR $111 \mathrm{~V}$ ), a new broad-spectrum cephalosporin. Antimicrob. Agents Chemother. 35:14-19.

McKellar, Q. A., S. F. Sanchez Bruni, and D. G. Jones. 2004. Pharmacokinetic/pharmacodynamic relationships of antimicrobial drugs used in veterinary medicine. J. Vet. Pharmacol. Ther. 27:503-514.

National Committee for Clinical Laboratory Standards. 2002. Performance Standards for Antimicrobial Disk and Dilution Susceptibility Tests for Bacteria Isolated from Animals. Approved Standard. Document M31-A2. 2nd ed. NCCLS (now CLSI), Wayne, PA.

National Mastitis Council. 1999. Laboratory Handbook on Bovine Mastitis. National Mastitis Council Inc., Madison, WI.

National Research Council. 2001. Nutrient Requirements of Dairy Cows. 7th rev. ed. National Academy Press, Washington, DC.

Oshima, M., and T. Yoshida. 1988. Quarter difference in milk hydrogen ion concentration is superior to milk $\mathrm{pH}$ for diagnosis of subclinical mastitis. Jpn. J. Zootech. Sci. 59:95-98.

Prescott, J. F. 2006. Beta-lactam antibiotics: Cephalosporins. Pages 139-157 in Antimicrobial Therapy in Veterinary Medicine. 4th ed. S. Giguere, J. F. Prescott, J. D. Baggot, R. D. Walker, P. M. Dowling, ed. Blackwell Publishing, Ames, IA.

Schmid, P., and V. Thomas. 2002. Cefquinome - Eight years of antimicrobial susceptibility surveillance in cattle. Proc. XXII World Buiatrics Congress, Hanover, Germany. 147:456-764.

Shpigel, N. Y., P. H. Kass, and A. Saran. 2006. A comparative randomized field trial on intramammary and intramuscular dry cow antibiotic treatment of subclinical Staphylococcus aureus mastitis in dairy cows. J. Vet. Med. A Physiol. Pathol. Clin. Med. $53: 418-422$.

Shpigel, N. Y., D. Levin, M. Winkler, A. Saran, G. Ziv, and A. Böttner. 1997. Efficacy of cefquinome for treatment of cows with 
mastitis experimentally induced using Escherichia coli. J. Dairy Sci. 80:318-323.

Shpigel, N. Y., and P. Schmid. 1997. Ein Beitrag zur Behandlung der akuten Mastitis des Rindes mit Cefquinom. Tierarztl. Prax. 25:200-206.

Stockler, R. M., D. E. Morin, R. K. Lantz, and P. D. Constable. 2009a. Effect of milking frequency and dosing interval on the pharmacokinetics of cephapirin after intramammary infusion in lactating dairy cows. J. Dairy Sci. 92:4262-4275.
Stockler, R. M., D. E. Morin, R. K. Lantz, W. L. Hurley, and P. D. Constable. 2009b. Effect of milk fraction on concentrations of cephapirin and desacetylcephapirin in bovine milk after intramammary infusion of cephapirin sodium. J. Vet. Pharmacol. Ther. $32: 345-352$.

Wagner, S., and R. Erskine. 2006. Antimicrobial drug use in bovine mastitis. Pages 507-517 in Antimicrobial Therapy in Veterinary Medicine. 4th ed. S. Giguere, J. F. Prescott, J. D. Baggot, R. D. Walker, P. M. Dowling, ed. Blackwell Publishing, Ames, IA. 